\title{
Psychosocial work characteristics as risk factors for the onset of fatigue and psychosocial distress: prospective results from the Maastricht Cohort Study.
}

Citation for published version (APA):

Bültmann, U., Kant, Y., van den Brandt, P. A., \& Kasl, S. V. (2002). Psychosocial work characteristics as risk factors for the onset of fatigue and psychosocial distress: prospective results from the Maastricht Cohort Study. Psychological Medicine, 32, 333-345. https://doi.org/10.1017/S0033291701005098

Document status and date:

Published: 01/01/2002

DOI:

10.1017/S0033291701005098

Document Version:

Publisher's PDF, also known as Version of record

Please check the document version of this publication:

- A submitted manuscript is the version of the article upon submission and before peer-review. There can be important differences between the submitted version and the official published version of record.

People interested in the research are advised to contact the author for the final version of the publication, or visit the DOI to the publisher's website.

- The final author version and the galley proof are versions of the publication after peer review.

- The final published version features the final layout of the paper including the volume, issue and page numbers.

Link to publication

\footnotetext{
General rights rights.

- You may freely distribute the URL identifying the publication in the public portal. please follow below link for the End User Agreement:

www.umlib.nl/taverne-license

Take down policy

If you believe that this document breaches copyright please contact us at:

repository@maastrichtuniversity.nl

providing details and we will investigate your claim.
}

Copyright and moral rights for the publications made accessible in the public portal are retained by the authors and/or other copyright owners and it is a condition of accessing publications that users recognise and abide by the legal requirements associated with these

- Users may download and print one copy of any publication from the public portal for the purpose of private study or research.

- You may not further distribute the material or use it for any profit-making activity or commercial gain

If the publication is distributed under the terms of Article $25 \mathrm{fa}$ of the Dutch Copyright Act, indicated by the "Taverne" license above, 


\title{
Psychosocial work characteristics as risk factors for the onset of fatigue and psychological distress: prospective results from the Maastricht Cohort Study
}

\author{
U. BÜLTMANN, ${ }^{1}$ IJ. KANT, P. A. VAN DEN BRANDT AND S. V. KASL
}

From the Department of Epidemiology, Maastricht University, Maastricht, The Netherlands; and Department of Epidemiology and Public Health, Yale University School of Medicine, New Haven, CT, USA

\begin{abstract}
Background. Prolonged fatigue has recently attracted attention in occupational (mental) health research since it may lead to sickness absenteeism and work disability. To date, little is known about the role of psychosocial work characteristics in the aetiology of fatigue. In this study we examined prospectively a wide range of psychosocial work characteristics as possible risk factors for the onset of fatigue and psychological distress in the working population.
\end{abstract}

Methods. This study is based on 8833 employees, participating in the Maastricht Cohort Study of 'Fatigue at Work'. A wide range of psychosocial work characteristics, measured at baseline, was used to predict the onset of fatigue and psychological distress 1 year later. Fatigue was measured with the Checklist Individual Strength; the General Health Questionnaire was used to measure psychological distress.

Results. The cumulative incidence of fatigue during 1 year follow-up was $9 \cdot 7 \%(N=492)$ in men, and $13.5 \%(N=241)$ in women. Psychological demands at work as well as physical and emotional demands increased the risk for fatigue in men, whereas decision latitude in men and coworker social support in women were protective against fatigue. These prospective associations remained significant after adjustments for potential confounders and baseline fatigue. As regards psychological distress, no association was found with decision latitude, while conflicts at work increased the risk of psychological distress.

Conclusions. Psychosocial work characteristics were significant predictors for the onset of fatigue in the working population. The prospective associations suggest some differential effects in the aetiology of fatigue and psychological distress. Good interpersonal relationships at work and high decision authority were demonstrated to be relevant aspects that should be targeted for prevention.

\section{INTRODUCTION}

Fatigue is a common symptom of ill-health (Chen, 1986; Pawlikowska et al. 1994; Hickie et al. 1996; Loge et al. 1998). Fatigue that becomes prolonged is reported to be associated with impairments comparable to chronic medical conditions (Kroenke et al. 1988) and may

1 Address for correspondence: Dr Ute Bültmann, Department of Epidemiology, Maastricht University, PO Box 616, 6200 MD Maastricht, The Netherlands. interfere with an individual's performance and functioning in the occupational as well as in the home setting. In recent years, prolonged fatigue has attracted attention in occupational (mental) health research, since it may lead to sickness absenteeism and work disability (Schröer, 1997). As pointed out by Houtman (1999), about one in every three work disability benefit recipients in the Netherlands is classified as disabled for work on mental grounds. Given the unfavourable prognosis of prolonged fatigue and the high cost implications for employers, employees and 
society (Schröer, 1997), there is an urgent need for preventive measures.

Recently, the large-scale epidemiological Maastricht Cohort Study of 'Fatigue at Work' has shown that fatigue is a common complaint in the working population: $22 \%$ of the 12000 employees reported fatigue (Bültmann et al. $2002 a$ ). For the development of preventive measures for sickness absenteeism and work disability due to fatigue, it is important to identify the risk factors for the onset of fatigue. While the likely multi-factorial aetiology of fatigue is stressed in the literature (Lewis \& Wessely, 1992) and 'psychosocial' (e.g. work, family and lifestyle) is the commonest mentioned reason for feeling fatigued (Pawlikowska et al. 1994), there is very little information about psychosocial work characteristics which predict fatigue.

At present, we do know from a cross-sectional study among specific occupational groups in the workforce of the UK National Health Service Trusts (Hardy et al. 1997) that high work demands and role conflict are related to high levels of fatigue. Moreover, cross-sectional analyses of the baseline data of the Maastricht Cohort Study revealed relationships between psychosocial work characteristics (e.g. low decision latitude, low social support at work, high emotional demands) on the one hand, and fatigue on the other (Bültmann et al. 2002b). The same study found that fatigue and psychological distress are fairly well associated in the working population $(r=0.62)$, and that about $23 \%$ of the 12000 employees were considered to be probable cases of psychological distress (Bültmann et al. 2002a).

To disentangle which psychosocial work characteristics play a role in the onset of fatigue and psychological distress, prospective longitudinal analyses are invaluable. Previous longitudinal studies such as the Whitehall II cohort of British civil servants (Stansfeld et al. 1997, 1999) and the Gazel cohort in France (Niedhammer et al. 1998) accumulated evidence for a relationship between psychosocial work characteristics and psychiatric disorder or depressive symptoms, respectively. Although their operationalization of psychosocial work characteristics and the occupational settings differ, these studies showed that low social support at work, high psychological demands, and low decision latitude (decision authority) were predictors of psychiatric disorder and depressive symptoms. As regards to fatigue, however, such prospective associations are not yet established. Moreover, the role of emotional and physical demands, job insecurity, and conflicts with supervisor/coworker as possible determinants of fatigue and psychological distress in the working population has rarely been examined.

In the present study we explored prospectively a wide range of psychosocial work characteristics as possible risk factors for fatigue and psychological distress in the working population, thereby comparing associations for fatigue and psychological distress. We examined this through the Maastricht Cohort Study, a largescale prospective study of 'Fatigue at Work'. The longitudinal relations between psychosocial work characteristics, measured at baseline, and (the incidence of) fatigue and psychological distress at follow-up 1 year later, were examined using linear regression analysis and logistic regression analysis. Both analyses controlled for potential sociodemographic confounding variables and for either fatigue or psychological distress, depending on the outcome assessed. Given the observed difference between men and women as regards to psychological distress, all analyses were conducted separately for men and women.

\section{METHOD}

\section{Sampling and procedures}

The present report is based on the Maastricht Cohort Study of 'Fatigue at Work', a largescale prospective study of the onset and natural history of fatigue and psychological distress in the working population (Bültmann et al. 2000; Kant et al. 2000). In May 1998, 26978 employees aged 18-65 years from 45 companies and organizations received a letter at home, inviting participation, and the self-administered baseline questionnaire, which included items on psychosocial work characteristics, demographic, workfamily and health factors as well as on fatigue and psychological distress. A total of 12161 employees completed and returned the baseline questionnaire (response rate of $45 \%$ ). Written consent was obtained from all participants. Sixty-six questionnaires were excluded from the analysis because the age criterion was not met 
and due to technical reasons. The baseline cohort consists of 8840 men $(73 \%)$ and 3255 women $(27 \%)$.

A non-response analysis revealed no significant differences between respondents and non-respondents with respect to demographic characteristics. Non-respondents were less likely to report fatigue complaints $\left(42 \% v .55 \%, \chi^{2}=\right.$ $11 \cdot 1, P<0 \cdot 05)$, sickness absence $(21 \%, v .39 \%$, $\left.\chi^{2}=21.5, P<0.05\right)$, and difficulties in work execution due to health complaints $(17 \%, v$. $\left.26 \%, \chi^{2}=7.75, P<0.05\right)$. The main reason for non-response was 'no time to complete the questionnaire' $(30 \%)$, followed by 'nothing would be done with the results' $(18 \%)$, and 'no interest in the study subject' $(15 \%)$. Full details of the sampling and the baseline characteristics of the study population have been reported elsewhere (Bültmann et al. 2002a).

In May 1999 , those employees $(N=11272)$ who had completed the baseline questionnaire and at least one of the two short questionnaires, which were sent in September 1998 and January 1999, were approached again to complete the follow-up questionnaire. Overall, 9625 employees, 7025 men $(73 \%)$ and 2600 women $(27 \%)$, completed and returned the follow-up questionnaire (response rate of $80 \%$ ). In the present analysis, we excluded those employees who reported themselves at baseline absent from work or reported working under modified conditions related to former sickness absence (e.g. fewer hours, modified tasks or other functions). Therefore, the final study population on whom follow-up data were available was 8833 employees, 6522 men $(74 \%)$ and 2311 women $(26 \%)$.

\section{Measurements}

\section{Psychosocial work characteristics}

All information on psychosocial work characteristics used in this study was obtained from the baseline questionnaire. A validated Dutch version of the Job Content Questionnaire (JCQ) was used to measure psychological demands, decision latitude and social support at work (Karasek, 1985; Houtman, 1995). Psychological demands are assessed by the sum of five items (excessive work, conflicting demands, insufficient time to do work, work fast and work hard). Decision latitude is measured by the sum of two subscales: skill discretion (keep learning new things, can develop skills, job requires skills, task variety, work not repetitious, job requires creativity) and decision authority (have freedom to make decisions, can choose how to perform work, and have a lot to say on the job). Social support is assessed by two scales, each consisting of four items: supervisor support (concerned about the welfare of those under him/her, pays attention, helpful in getting the job done, successful in getting people to work together) and co-worker support (they take a personal interest in me, are friendly, helpful in getting the job done, and competent in doing work). For each item the response options varied on a fourpoint scale from 'strongly disagree' to 'strongly agree'. In the logistic regression analysis, the total scores for psychological demands and decision latitude were grouped into tertiles, for both support measures the total score was dichotomized at the median.

Emotional demands at work are measured by the sum of five items (confronted with personally upsetting things, personal attacked or threaten, getting annoyed about others, moving work situations, and one or more shocking events at work during last year e.g. accident, violent crime, sexual harassment, aggression at work). The questions were derived from a Dutch questionnaire on Work and Health (Gründemann et al. 1993), a Dutch questionnaire on Perception and Judgement of Work (Van Veldhoven \& Meijman, 1994), and selfformulated (item on shocking events at work). The response option for each item was yes/no. In the present study, emotional demands at work was indicated as no emotional demands $($ score $=0)$, low emotional demands $($ score $=1)$, and high emotional demands (score $=2-5$ ).

To assess whether employees perceive their work as physically demanding (yes/no), one item from the Dutch questionnaire on Work and Health (Gründemann et al. 1993) was used. Three items from the Dutch questionnaire on Perception and Judgement of Work (Van Veldhoven \& Meijman, 1994) were used to measure job insecurity (yes/no), conflicts with supervisor (yes/no) and conflicts with coworkers (yes/no).

\section{Demographic and health factors}

At baseline employees provided information on age, educational level, living alone (yes/no), 
status of employment (permanent contract or temporary contract) and the presence of disease (yes/no), comprising for example chronic low back pain, rheumatoid arthritis and hypertension. Details of these measures, which are considered in the analyses as confounding factors, have been reported elsewhere (Bültmann et al. 2002a).

\section{Fatigue}

The 20-item self-report Checklist Individual Strength (CIS), which was originally developed for hospital studies of chronic fatigue syndrome, was used to measure fatigue (Vercoulen et al. 1994, 1999). The CIS covers several aspects of fatigue, such as severity, concentration, motivation and physical activity level, which fit in with the concept of fatigue. The instrument was extensively tested in the clinical setting (Vercoulen et al. 1996a, b) and was validated in the working population (Beurskens et al. 2000). Subjects are instructed to indicate how they felt during the last 2 weeks. The response to each statement is scored on a 7-point Likert scale $(1=$ Yes, that is true; to, $7=$ No, that is not true). Higher scores indicate a higher degree of fatigue, more concentration problems, reduced motivation or low levels of activity. In the Maastricht Cohort Study, the responses to the individual items were summed to generate a CIS-total score, ranging from 20-140. The cut-off point for case classification used in the present study was CIS-total $>76$. This cut-off was established in a separate pilot study by means of defined samples with differences in fatigue levels (Bültmann et al. 2000). All those employees scoring $>76$ on the CIS were considered to report a level of fatigue indicative of being 'at risk' for sickness absence or work disability, and were designated as probable fatigue cases.

\section{Psychological distress}

The 12-item version of the General Health Questionnaire (GHQ-12) was used to assess psychological distress (Goldberg \& Williams 1988; Koeter \& Ormel 1991). The GHQ-12 was developed as a screening instrument for detecting minor psychiatric disorders in the general population. Two scoring systems were used for the four-point response scale. The Likert scoring method $(0,1,2,3)$ summed the responses of the
12 items to generate a continuous distribution, ranging from $0-36$. The traditional GHQ scoring method $(0,0,1,1)$ is designed to identify individuals reporting sufficient psychological distress to be classified as probable cases of minor psychiatric disorder. In the present study, the threshold for case classification was $\geqslant 4$, given a possible range of scores from $0-12$. That means, employees scoring on $\geqslant 4$ of the 12 items were considered to be probable cases of psychological distress. The threshold for case classification is high, but identical to the threshold used in previous workplace studies (Hardy et al. 1997; Wall et al. 1997), permitting direct comparison of the results, and likely to indicate very symptomatic employees as probable cases of minor psychiatric disorder.

\section{Data analysis}

All analyses were performed separately for men and women because of the observed gender difference regarding psychological distress (Bültmann et al. 2002a). Pearson intercorrelations were calculated for the psychosocial work characteristics and the cumulative incidence of fatigue and psychological distress during 1-year follow-up period was determined. To examine the role of psychosocial work characteristics, measured at baseline, in the onset of fatigue and psychological distress after 1-year follow-up, the data were analysed using two methods. The primary analysis was linear regression analysis, which makes no assumptions about a diagnostic cut-off point and therefore fully reflects the continuous nature of the dependent measures. In addition, logistic regression analysis with dichotomized dependent measures was used. Data were analysed using SPSS 9.0 (SPSS, 1998).

Multiple linear regression analysis was used to examine the effect of each psychosocial work characteristic separately on changes in fatigue and psychological distress 1 year later. Additionally, given there are intercorrelations among the psychosocial work characteristics, the predictive effects of psychosocial work characteristics for future fatigue and psychological distress were examined by entering them all together, rather than one at a time. Adjustments for potential confounding variables were made in three steps: covariates age; educational 
Table 1. Correlation matrix of psychosocial work characteristics for men (bold type face,

$\mathrm{N}=6522)$ and women $(\mathrm{N}=2311)$

\begin{tabular}{|c|c|c|c|c|c|c|c|c|c|}
\hline 1 Psychological job demands & & $0 \cdot 03 *$ & $-\mathbf{0} \cdot 20 * *$ & $-0 \cdot 05^{* *}$ & $0 \cdot 26^{* *}$ & $0 \cdot 18^{* *}$ & $\mathbf{0} \cdot 15^{* *}$ & $0 \cdot 07 * *$ & $0 \cdot 05^{* *}$ \\
\hline 2 Decision latitude & $0 \cdot 06^{* *}$ & & $\mathbf{0} 35^{* *}$ & $\mathbf{0} 23^{* *}$ & $-0 \cdot 14^{* *}$ & $-\mathbf{0} \cdot 32 * *$ & $-0 \cdot 15^{* *}$ & $-0 \cdot 05^{* *}$ & $-0 \cdot 15^{* *}$ \\
\hline 4 Co-worker social support & $-0.09 * *$ & $0 \cdot 16^{* *}$ & $0 \cdot 30 * *$ & & $-\mathbf{0} \cdot 17^{* *}$ & $-0.07 * *$ & $-0 \cdot 07 * *$ & $-\mathbf{0} \cdot 24^{* *}$ & $-0 \cdot 12 * *$ \\
\hline 5 Emotional demands & $0 \cdot 24 * *$ & $-0 \cdot 02$ & $-0 \cdot 15^{* *}$ & $-0 \cdot 09^{* *}$ & & $0 \cdot 26^{* *}$ & $0 \cdot 29^{* *}$ & $\mathbf{0} \cdot 26^{* *}$ & $0 \cdot 19 * *$ \\
\hline 6 Physical demands & $0 \cdot 19^{* *}$ & $-0 \cdot 12 * *$ & -0.02 & $0 \cdot 01$ & $0 \cdot 31 * *$ & & $0 \cdot 11^{* *}$ & $0 \cdot 06^{* *}$ & $0.08 * *$ \\
\hline 9 Job insecurity & $0 \cdot 03$ & $-0 \cdot 13 * *$ & $-0 \cdot 14 * *$ & $-0 \cdot 07 * *$ & $0 \cdot 07 * *$ & $-0 \cdot 02$ & $0 \cdot 07 * *$ & $0 \cdot 03$ & \\
\hline
\end{tabular}

Correlation significant at: ${ }^{*} P<0 \cdot 05 ; * * P<0 \cdot 01$.

Table 2. Work characteristics at baseline predict fatigue after 1-year follow-up in men and women, adjusted for potential confounders and baseline measures

\begin{tabular}{|c|c|c|c|c|c|c|}
\hline \multirow{3}{*}{ Work characteristic } & \multicolumn{6}{|c|}{$\operatorname{Men}(N=6522)$} \\
\hline & \multicolumn{2}{|c|}{ Model $1 \dagger$} & \multicolumn{2}{|c|}{ Model 2末 } & \multicolumn{2}{|c|}{ Model $3 \S$} \\
\hline & $\mathrm{B}$ & S.E. & $\mathrm{B}$ & S.E. & $\mathrm{B}$ & S.E. \\
\hline Psychological demands & $0.632 * * *$ & $0 \cdot 052$ & $0 \cdot 184 * * *$ & 0.037 & $0 \cdot 140 * * *$ & $0 \cdot 038$ \\
\hline Decision latitude & $-0 \cdot 493 * * *$ & $0 \cdot 027$ & $-0 \cdot 103 * * *$ & $0 \cdot 020$ & $-0.094 * * *$ & 0.020 \\
\hline Supervisor support & $-1.529 * * *$ & $0 \cdot 128$ & -0.093 & 0.093 & $0 \cdot 0008$ & 0.093 \\
\hline Co-worker support & $-1 \cdot 589 * * *$ & $0 \cdot 188$ & $-0 \cdot 135$ & $0 \cdot 135$ & -0.088 & $0 \cdot 135$ \\
\hline Physical demands & $8 \cdot 159 * * *$ & $0 \cdot 784$ & $2 \cdot 213 * * *$ & 0.563 & $1.958 * *$ & 0.564 \\
\hline Emotional demands & $4 \cdot 016^{* * *}$ & $0 \cdot 236$ & $0 \cdot 882 * * *$ & $0 \cdot 175$ & $0.624 * * *$ & $0 \cdot 179$ \\
\hline Job insecurity & $7 \cdot 488 * * *$ & $1 \cdot 129$ & -0.939 & 0.807 & $-1 \cdot 658^{*}$ & $0 \cdot 809$ \\
\hline Conflicts supervisor & $8 \cdot 712 * * *$ & 0.975 & $1 \cdot 012$ & 0.698 & $0 \cdot 404$ & $0 \cdot 701$ \\
\hline \multirow[t]{3}{*}{ Conflicts co-worker } & $6.737 * * *$ & $1 \cdot 117$ & $1 \cdot 548$ & $0 \cdot 791$ & $0 \cdot 941$ & 0.793 \\
\hline & \multicolumn{6}{|c|}{ Women $(N=2311)$} \\
\hline & B & S.E. & B & S.E. & B & S.E. \\
\hline Psychological demands & $0 \cdot 427 * * *$ & $0 \cdot 095$ & -0.007 & $0 \cdot 080$ & $-0 \cdot 011$ & $0 \cdot 081$ \\
\hline Decision latitude & $-0 \cdot 313 * * *$ & $0 \cdot 051$ & $-0 \cdot 073$ & $0 \cdot 043$ & -0.071 & $0 \cdot 044$ \\
\hline Supervisor support & $-1.539 * * *$ & $0 \cdot 233$ & $-0 \cdot 222$ & $0 \cdot 200$ & $-0 \cdot 215$ & $0 \cdot 203$ \\
\hline Co-worker support & $-2 \cdot 226^{* * *}$ & $0 \cdot 330$ & $-1 \cdot 112 * * *$ & $0 \cdot 279$ & $-1 \cdot 105^{* * *}$ & $0 \cdot 281$ \\
\hline Physical demands & $3 \cdot 967 * *$ & $1 \cdot 250$ & 1.881 & $1 \cdot 042$ & 1.801 & 1.049 \\
\hline Emotional demands & $1.924 * * *$ & $0 \cdot 422$ & $0 \cdot 274$ & $0 \cdot 358$ & $0 \cdot 243$ & $0 \cdot 364$ \\
\hline Job insecurity & $6 \cdot 326^{* *}$ & 1.967 & $1 \cdot 202$ & 1.642 & $1 \cdot 113$ & 1.652 \\
\hline Conflicts supervisor & $8 \cdot 377 * * *$ & $2 \cdot 123$ & $2 \cdot 062$ & 1.787 & 1.973 & 1.823 \\
\hline Conflicts co-worker & $9 \cdot 015 * * *$ & $2 \cdot 243$ & $2 \cdot 759$ & 1.888 & 2.795 & 1.904 \\
\hline
\end{tabular}

$\dagger$ Adjusted for age, educational level, living alone, employment status and presence of disease

* Adjusted for age, educational level, living alone, employment status, presence of disease and baseline CIS score (continuous).

$\S$ Adjusted for age, educational level, living alone, employment status, presence of disease, baseline CIS score (continuous) and baseline GHQ score (continuous).

* $P<0.05$; ** $P<0.01$; *** $P<0.001$.

level; living alone; employment status; and, presence of disease were entered at the first step. At the second step, we also controlled for the continuous baseline values of the dependent measure. Finally, since fatigue and psychological distress are fairly well associated, we adjusted for the continuous baseline value of GHQ-12 or CIS score, when fatigue or psychological distress was considered as dependent variable, respectively. Unstandardized regression coefficients (B) and their standard errors (S.E. B) were determined for each model.

Multiple logistic regression was conducted in two steps for each psychosocial work characteristic separately. Either fatigue or psychological distress cases at baseline were excluded. 
Table 3. Work characteristics at baseline predict psychological distress after 1-year follow-up in men and women, adjusted for potential confounders and baseline measures

\begin{tabular}{|c|c|c|c|c|c|c|}
\hline \multirow{3}{*}{ Work characteristic } & \multicolumn{6}{|c|}{$\operatorname{Men}(N=6522)$} \\
\hline & \multicolumn{2}{|c|}{ Model $1 \uparrow$} & \multicolumn{2}{|c|}{ Model 2末 } & \multicolumn{2}{|c|}{ Model $3 \S$} \\
\hline & B & S.E. & $\mathrm{B}$ & S.E. & B & S.E. \\
\hline Psychological demands & $0 \cdot 158^{* * *}$ & $0 \cdot 011$ & $0 \cdot 068 * * *$ & $0 \cdot 010$ & $0 \cdot 064 * * *$ & $0 \cdot 010$ \\
\hline Decision latitude & $-0.063 * * *$ & $0 \cdot 006$ & $-0 \cdot 021 * * *$ & 0.005 & $-0 \cdot 010$ & $0 \cdot 005$ \\
\hline Supervisor support & $-0 \cdot 293 * * *$ & $0 \cdot 027$ & $-0.072 * *$ & $0 \cdot 024$ & $-0 \cdot 046$ & $0 \cdot 024$ \\
\hline Co-worker support & $-0 \cdot 276^{* * *}$ & $0 \cdot 040$ & $-0.077 * *$ & 0.035 & -0.038 & 0.035 \\
\hline Physical demands & $1 \cdot 291 * * *$ & $0 \cdot 167$ & $0 \cdot 484^{* *}$ & $0 \cdot 148$ & $0 \cdot 345^{*}$ & $0 \cdot 148$ \\
\hline Emotional demands & $0.906^{* * *}$ & $0 \cdot 050$ & $0 \cdot 345^{* * *}$ & $0 \cdot 047$ & $0 \cdot 302 * * *$ & $0 \cdot 047$ \\
\hline Job insecurity & $1 \cdot 804^{* * *}$ & $0 \cdot 237$ & $0 \cdot 304$ & $0 \cdot 211$ & $0 \cdot 202$ & $0 \cdot 211$ \\
\hline Conflicts supervisor & $2 \cdot 079 * * *$ & $0 \cdot 205$ & $0.697 * * *$ & $0 \cdot 184$ & $0.600^{* *}$ & $0 \cdot 183$ \\
\hline \multirow[t]{3}{*}{ Conflicts co-worker } & $1 \cdot 876^{* * *}$ & $0 \cdot 236$ & $0 \cdot 634 * *$ & $0 \cdot 209$ & $0 \cdot 579 * *$ & $0 \cdot 208$ \\
\hline & \multicolumn{6}{|c|}{ Women $(N=2311)$} \\
\hline & $\mathrm{B}$ & S.E. & $\mathrm{B}$ & S.E. & B & S.E. \\
\hline Psychological demands & $0 \cdot 095^{* * *}$ & $0 \cdot 021$ & $0 \cdot 020$ & $0 \cdot 020$ & $0 \cdot 011$ & $0 \cdot 020$ \\
\hline Decision latitude & $-0.032 * *$ & $0 \cdot 011$ & $0 \cdot 0004$ & $0 \cdot 011$ & $0 \cdot 007$ & $0 \cdot 011$ \\
\hline Supervisor support & $-0 \cdot 217 * * *$ & $0 \cdot 052$ & -0.021 & $0 \cdot 050$ & $0 \cdot 021$ & $0 \cdot 050$ \\
\hline Co-worker support & $-0 \cdot 317 * * *$ & 0.075 & $-0 \cdot 111$ & 0.070 & -0.097 & $0 \cdot 070$ \\
\hline Physical demands & $0.666^{*}$ & $0 \cdot 282$ & $0 \cdot 331$ & $0 \cdot 261$ & $0 \cdot 281$ & $0 \cdot 262$ \\
\hline Emotional demands & $0 \cdot 502 * * *$ & 0.095 & $0 \cdot 157$ & 0.090 & $0 \cdot 113$ & $0 \cdot 090$ \\
\hline Job insecurity & $1 \cdot 100^{*}$ & $0 \cdot 443$ & $0 \cdot 254$ & $0 \cdot 411$ & $0 \cdot 202$ & $0 \cdot 410$ \\
\hline Conflicts supervisor & $1.620 * *$ & $0 \cdot 476$ & $0 \cdot 196$ & $0 \cdot 449$ & $0 \cdot 189$ & $0 \cdot 453$ \\
\hline Conflicts co-worker & $1 \cdot 261 *$ & $0 \cdot 508$ & $0 \cdot 063$ & $0 \cdot 473$ & -0.078 & $0 \cdot 480$ \\
\hline
\end{tabular}

$\dagger$ Adjusted for age, educational level, living alone, employment status and presence of disease.

* Adjusted for age, educational level, living alone, employment status, presence of disease and baseline GHQ score (continuous).

$\S$ Adjusted for age, educational level, living alone, employment status, presence of disease, baseline GHQ score (continuous) and baseline CIS score (continuous).

* $P<0.05$; ** $P<0.01$; *** $P<0.001$.

Because a simple incidence analysis ignores the issue that those close to the CIS cut-off and making only small changes will be counted as incident cases, we introduced the refinement that they also have to have an increase of a certain size. The size was determined by calculating the mean within person variance for baseline and follow-up CIS measurement ( 8 points). Then the delta CIS score, which is the follow-up CIS score minus the baseline CIS score, was calculated for all employees. Hence, those who crossed the predefined CIS cut-off of $>76$ at follow-up and had a delta CIS $\leqslant 8$ were excluded from the analysis. In a first step, we adjusted for age, educational level, living alone, employment status, and presence of disease. Since fatigue and psychological distress are fairly well associated, we adjusted in a second step for the continuous baseline GHQ-12 or CIS score, when subsequent fatigue or psychological distress was considered as dependent variable, respectively. Odds ratios (ORs) and their $95 \%$ confidence intervals ( $95 \%$
CIs) were calculated for each psychosocial work characteristic.

\section{RESULTS}

\section{Intercorrelations of psychosocial work characteristics}

Table 1 shows the Pearson intercorrelations of all psychosocial work characteristics for men and women separately. In both genders, the highest correlation was observed between supervisor social support and conflicts with supervisor $(r=-0.37, N=6394, P<0.01$ in men; $r=$ $-0.31, N=2259, P<0.01$ in women). Overall, psychosocial work characteristics were rather weakly correlated with each other.

\section{Work characteristics at baseline predicting fatigue at follow-up}

In men and women, the linear regression analyses of each psychosocial work characteristics separately showed that after adjustment for po- 
Table 4. Prospective associations between work characteristics and the onset of fatigue in men $(\mathrm{N}=5036)$, adjusted for potential confounders and baseline GHQ score

\begin{tabular}{|c|c|c|c|c|}
\hline Work characteristic & $\mathrm{OR} \dagger$ & $95 \% \mathrm{CI}$ & OR: & $95 \% \mathrm{CI}$ \\
\hline $\begin{array}{l}\text { Psychological deman } \\
\text { High } \\
\text { Medium } \\
\text { Low }\end{array}$ & $\begin{array}{l}1 \cdot 61 \\
1 \cdot 42 \\
1\end{array}$ & $\begin{array}{l}1 \cdot 27-2 \cdot 04 \\
1 \cdot 10-1 \cdot 82\end{array}$ & $\begin{array}{l}1 \cdot 28 \\
1 \cdot 23 \\
1\end{array}$ & $\begin{array}{l}1.00-1.64 \\
0.95-1.59\end{array}$ \\
\hline $\begin{array}{l}\text { Decision latitude } \\
\text { Low } \\
\text { Medium } \\
\text { High }\end{array}$ & $\begin{array}{l}1 \cdot 87 \\
0 \cdot 91 \\
1\end{array}$ & $\begin{array}{l}1 \cdot 46-2 \cdot 40 \\
0 \cdot 70-1 \cdot 17\end{array}$ & $\begin{array}{l}1 \cdot 59 \\
0 \cdot 88 \\
1\end{array}$ & $\begin{array}{l}1 \cdot 23-2 \cdot 06 \\
0 \cdot 68-1 \cdot 14\end{array}$ \\
\hline $\begin{array}{l}\text { Supervisor social sur } \\
\text { Low } \\
\text { High }\end{array}$ & $\begin{array}{l}1 \cdot 62 \\
1\end{array}$ & $1.33-1.98$ & $\begin{array}{l}1 \cdot 38 \\
1\end{array}$ & $1 \cdot 12-1.69$ \\
\hline $\begin{array}{l}\text { Co-worker social su } \\
\text { Low } \\
\text { High }\end{array}$ & $\begin{array}{l}1 \cdot 57 \\
1\end{array}$ & $1.29-1.93$ & $\begin{array}{l}1 \cdot 45 \\
1\end{array}$ & $1 \cdot 18-1.78$ \\
\hline $\begin{array}{l}\text { Physical demands } \\
\text { Yes } \\
\text { No }\end{array}$ & $\begin{array}{l}1 \cdot 54 \\
1\end{array}$ & $1 \cdot 20-1.98$ & $\begin{array}{l}1 \cdot 32 \\
1\end{array}$ & $1.02-1 \cdot 72$ \\
\hline $\begin{array}{l}\text { Emotional demands } \\
\text { High } \\
\text { Low } \\
\text { No }\end{array}$ & $\begin{array}{l}2 \cdot 01 \\
1 \cdot 23 \\
1\end{array}$ & $\begin{array}{l}1.59-2.54 \\
0.96-1.57\end{array}$ & $\begin{array}{l}1 \cdot 47 \\
1 \cdot 12 \\
1\end{array}$ & $\begin{array}{l}1 \cdot 14-1 \cdot 88 \\
0.87-1.44\end{array}$ \\
\hline $\begin{array}{l}\text { Conflicts supervisor } \\
\text { Yes } \\
\text { No }\end{array}$ & $\begin{array}{l}1 \cdot 60 \\
1\end{array}$ & $1 \cdot 18-2 \cdot 17$ & $\begin{array}{l}1 \cdot 20 \\
1\end{array}$ & $0 \cdot 87-1 \cdot 65$ \\
\hline $\begin{array}{l}\text { Conflicts co-worker } \\
\text { Yes } \\
\text { No }\end{array}$ & $\begin{array}{l}1 \cdot 49 \\
1\end{array}$ & $1 \cdot 05-2 \cdot 11$ & $\begin{array}{l}1 \cdot 17 \\
1\end{array}$ & $0.81-1.68$ \\
\hline $\begin{array}{l}\text { Job insecurity } \\
\text { Yes } \\
\text { No }\end{array}$ & $\begin{array}{l}1 \cdot 28 \\
1\end{array}$ & $0 \cdot 87-1 \cdot 89$ & $\begin{array}{l}0 \cdot 93 \\
1\end{array}$ & $0.62-1.39$ \\
\hline
\end{tabular}

$\dagger$ Adjusted for age, educational level, living alone, employment status and presence of disease.

* Adjusted for age, educational level, living alone, employment status, presence of disease and baseline GHQ score (continuous).

tential confounding variables, all psychosocial work characteristics were significantly associated with fatigue (Table 2, Model 1). In men, when controlled for baseline CIS score, psychological, physical and emotional demands as well as conflicts with co-worker were related to higher CIS scores, whereas decision latitude was significantly associated with lower CIS scores (Model 2). Lower CIS scores were also related to the two original subscales of decision latitude, skill discretion and decision authority, though stronger with decision authority (specific data not shown). While most associations remained significant after additional adjustment for baseline GHQ score, the association between conflicts with co-worker and fatigue was explained away (Model 3). For job insecurity a negative association with fatigue was found after control for both baseline measures. Given the weak to modest intercorrelations among the predictors, the analyses of all psychosocial work characteristics together, adjusted for potential confounding variables and the baseline measures, showed similar effects for the various work characteristics as the effects seen in the separate analyses (specific data not shown).

As shown in Table 2, among women only coworker social support was significantly related to lower CIS scores after adjustment for baseline CIS score and also after additional adjustment for baseline GHQ score. The finding was confirmed when all psychosocial work characteristics were entered together (specific data not shown).

\section{Work characteristics at baseline predicting psychological distress at follow-up}

As presented in Table 3, in men and women each psychosocial work characteristic separately was significantly associated with psychological dis- 
Table 5. Prospective associations between work characteristics and the onset of fatigue in women $(\mathrm{N}=1787)$, adjusted for potential confounders and baseline GHQ score

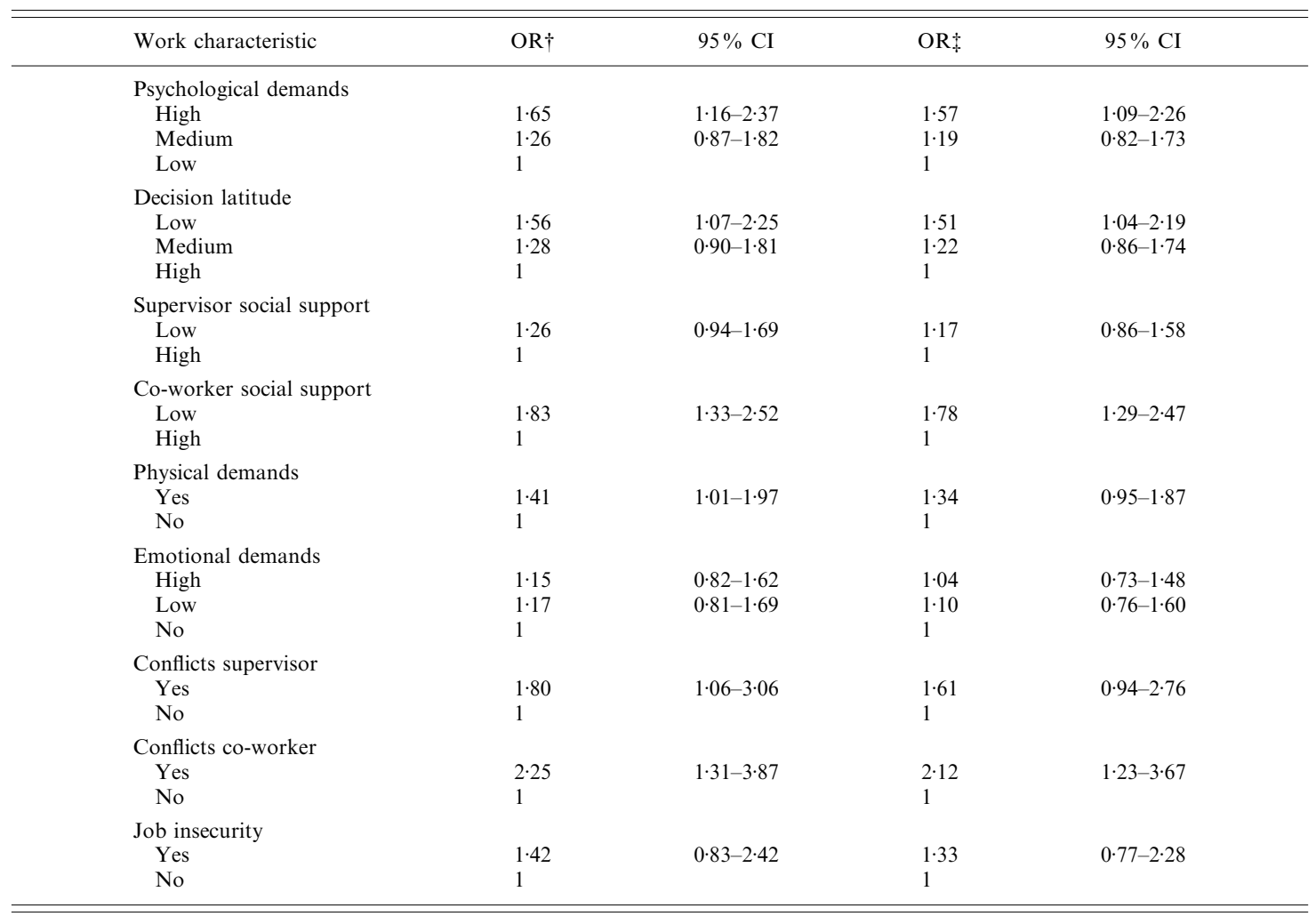

$\dagger$ Adjusted for age, educational level, living alone, employment status and presence of disease.

* Adjusted for age, educational level, living alone, employment status, presence of disease and baseline GHQ score (continuous).

tress (Model 1). In men, only job insecurity was no longer significant after adjustment for baseline GHQ score (Model 2). When we also controlled for baseline CIS score, psychological, physical and emotional demands as well as conflicts with co-worker and supervisor were still significantly related to higher GHQ scores, while decision authority (specific data not shown) was significantly associated with lower GHQ scores. When all psychosocial work characteristics were analysed together and adjusted for potential confounders as well as baseline measures, the predictive effects of psychosocial work characteristics were found to be similar to those obtained in the separate analyses (specific data not shown).

In women, all associations between the separate psychosocial work characteristics and psychological distress were weakened and no longer significant after control for baseline GHQ score (Model 2). The analyses of all psychosocial work characteristics together confirmed the finding of the separate analyses (specific data not shown).

\section{Work characteristics at baseline predicting fatigue caseness}

In the supplementary logistic regression analysis 66 cases (53 men and 13 women) were excluded because of a delta $\mathrm{ClS} \leqslant 8$, even though their follow-up score was above the cut-off. The cumulative incidence of fatigue during 1 year follow-up was $9.7 \%(N=492)$ in men, and $13.5 \%(N=241)$ in women. In both genders significant associations between psychosocial work characteristics and fatigue were found. As shown in Table 4, in men all psychosocial work characteristics, except job insecurity, were significantly associated with fatigue. Although the odds ratios were reduced in size after adjustment 
Table 6. Prospective associations between work characteristics and the onset of psychological distress in men $(\mathrm{N}=5243)$, adjusted for potential confounders and baseline CIS score

\begin{tabular}{|c|c|c|c|c|}
\hline Work characteristic & $\mathrm{OR} \dagger$ & $95 \% \mathrm{CI}$ & OR: & $95 \%$ CI \\
\hline $\begin{array}{l}\text { Psychological deman } \\
\text { High } \\
\text { Medium } \\
\text { Low }\end{array}$ & $\begin{array}{l}1 \cdot 63 \\
1 \cdot 20 \\
1\end{array}$ & $\begin{array}{l}1 \cdot 33-2 \cdot 00 \\
0 \cdot 96-1 \cdot 50\end{array}$ & $\begin{array}{l}1 \cdot 51 \\
1 \cdot 16 \\
1\end{array}$ & $\begin{array}{l}1 \cdot 23-1 \cdot 85 \\
0 \cdot 93-1 \cdot 45\end{array}$ \\
\hline $\begin{array}{l}\text { Decision latitude } \\
\text { Low } \\
\text { Medium } \\
\text { High }\end{array}$ & $\begin{array}{l}1 \cdot 43 \\
0 \cdot 89 \\
1\end{array}$ & $\begin{array}{l}1 \cdot 15-1 \cdot 78 \\
0 \cdot 72-1 \cdot 10\end{array}$ & $\begin{array}{l}1 \cdot 14 \\
0 \cdot 82 \\
1\end{array}$ & $\begin{array}{l}0.90-1 \cdot 43 \\
0.66-1.02\end{array}$ \\
\hline $\begin{array}{l}\text { Supervisor social sup } \\
\text { Low } \\
\text { High }\end{array}$ & $\begin{array}{l}1 \cdot 39 \\
1\end{array}$ & $1 \cdot 17-1 \cdot 65$ & $\begin{array}{l}1 \cdot 25 \\
1\end{array}$ & $1.05-1.49$ \\
\hline $\begin{array}{l}\text { Co-worker social sup } \\
\text { Low } \\
\text { High }\end{array}$ & $\begin{array}{l}1 \cdot 38 \\
1\end{array}$ & $1 \cdot 15-1 \cdot 65$ & $\begin{array}{l}1 \cdot 25 \\
1\end{array}$ & $1.04-1.49$ \\
\hline $\begin{array}{l}\text { Physical demands } \\
\text { Yes } \\
\text { No }\end{array}$ & $\begin{array}{l}1 \cdot 21 \\
1\end{array}$ & $0.96-1.53$ & $\begin{array}{l}1 \cdot 05 \\
1\end{array}$ & $0.83-1.34$ \\
\hline $\begin{array}{l}\text { Emotional demands } \\
\text { High } \\
\text { Low } \\
\text { No }\end{array}$ & $\begin{array}{l}1.94 \\
1.33 \\
1\end{array}$ & $\begin{array}{l}1.57-2.39 \\
1.08-1.63\end{array}$ & $\begin{array}{l}1 \cdot 73 \\
1.23 \\
1\end{array}$ & $\begin{array}{l}1 \cdot 40-2 \cdot 14 \\
1 \cdot 00-1.52\end{array}$ \\
\hline $\begin{array}{l}\text { Conflicts supervisor } \\
\text { Yes } \\
\text { No }\end{array}$ & $\begin{array}{l}1 \cdot 93 \\
1\end{array}$ & $1 \cdot 48-2 \cdot 52$ & $\begin{array}{l}1.75 \\
1\end{array}$ & $1 \cdot 34-2 \cdot 30$ \\
\hline $\begin{array}{l}\text { Conflicts co-worker } \\
\text { Yes } \\
\text { No }\end{array}$ & $\begin{array}{l}1 \cdot 49 \\
1\end{array}$ & $1 \cdot 08-2 \cdot 06$ & $\begin{array}{l}1 \cdot 36 \\
1\end{array}$ & $0.98-1.89$ \\
\hline $\begin{array}{l}\text { Job insecurity } \\
\text { Yes } \\
\text { No }\end{array}$ & $\begin{array}{l}1 \cdot 83 \\
1\end{array}$ & $1 \cdot 33-2 \cdot 51$ & $\begin{array}{l}1 \cdot 63 \\
1\end{array}$ & $1 \cdot 18-2 \cdot 27$ \\
\hline
\end{tabular}

$\dagger$ Adjusted for age, educational level, living alone, employment status and presence of disease.

\$ Adjusted for age, educational level, living alone, employment status, presence of disease and baseline CIS score (continuous).

for baseline GHQ score, the onset of fatigue was predicted by low decision latitude $(\mathrm{OR}=1.59$ $95 \%$ confidence interval $(1 \cdot 23-2 \cdot 06))$, high emotional demands $(\mathrm{OR}=1 \cdot 47(1 \cdot 14-1 \cdot 88))$ and low social support at work. As regards the original subscales of decision latitude, low decision authority $(\mathrm{OR}=1.73(1.34-2.23))$ was strongly predictive for the onset of fatigue, whereas low skill discretion was no longer related to fatigue (not shown). For conflicts with coworker and supervisor the associations were explained away.

In women, the ORs for physical demands and conflicts with supervisor were reduced in size after control for baseline GHQ score and these characteristics were no longer related to the onset of fatigue (Table 5). Strong predictors for the onset of fatigue were conflicts with coworker $(\mathrm{OR}=2.12(1.23-3.67))$ and low coworker social support $(\mathrm{OR}=1.78(1.29-2 \cdot 47))$.
High psychological demands and low decision latitude, in particular low decision authority $(\mathrm{OR}=1.71$ (1.18-2.49); not shown), were also predictive for the onset of fatigue.

\section{Work characteristics at baseline predicting psychological distress caseness}

The cumulative incidence of psyhological distress during 1 year follow-up was $12 \cdot 6 \%(N=$ $657)$ in men, and $18.2 \%(N=321)$ in women. Table 6 shows that in men, except for physical demands, significant associations were found between psychosocial work characteristics and the onset of psychological distress. Of these, conflicts with supervisor $(\mathrm{OR}=1.75 \quad(1.34$ $2 \cdot 30)$ ), high emotional demands $(\mathrm{OR}=1.73$ $(1 \cdot 40-2 \cdot 14)$ ), job insecurity and high psychological demands were still predictive for the onset of psychological distress after adjustment for baseline CIS score, whereas the associations 
Table 7. Prospective associations between work characteristics and the onset of psychological distress in women $(\mathrm{N}=1785)$, adjusted for potential confounders and baseline CIS score

\begin{tabular}{|c|c|c|c|c|}
\hline Work characteristic & $\mathrm{OR} \dagger$ & $95 \% \mathrm{CI}$ & OR: & $95 \%$ CI \\
\hline $\begin{array}{l}\text { Psychological deman } \\
\text { High } \\
\text { Medium } \\
\text { Low }\end{array}$ & $\begin{array}{l}1 \cdot 59 \\
1 \cdot 24 \\
1\end{array}$ & $\begin{array}{l}1 \cdot 15-2 \cdot 19 \\
0 \cdot 90-1 \cdot 70\end{array}$ & $\begin{array}{l}1 \cdot 44 \\
1 \cdot 20 \\
1\end{array}$ & $\begin{array}{l}1 \cdot 03-2.01 \\
0.86-1.66\end{array}$ \\
\hline $\begin{array}{l}\text { Decision latitude } \\
\text { Low } \\
\text { Medium } \\
\text { High }\end{array}$ & $\begin{array}{l}1 \cdot 01 \\
0 \cdot 90 \\
1\end{array}$ & $\begin{array}{l}0 \cdot 73-1 \cdot 41 \\
0 \cdot 66-1.23\end{array}$ & $\begin{array}{l}0 \cdot 88 \\
0 \cdot 85 \\
1\end{array}$ & $\begin{array}{l}0.62-1 \cdot 24 \\
0.62-1 \cdot 17\end{array}$ \\
\hline $\begin{array}{l}\text { Supervisor social sup } \\
\text { Low } \\
\text { High }\end{array}$ & $\begin{array}{l}1 \cdot 30 \\
1\end{array}$ & $1 \cdot 00-1 \cdot 70$ & $\begin{array}{l}1 \cdot 12 \\
1\end{array}$ & $0 \cdot 85-1 \cdot 47$ \\
\hline $\begin{array}{l}\text { Co-worker social sup } \\
\text { Low } \\
\text { High }\end{array}$ & $\begin{array}{l}1 \cdot 40 \\
1\end{array}$ & $1 \cdot 05-1 \cdot 89$ & $\begin{array}{l}1 \cdot 31 \\
1\end{array}$ & $0.97-1.78$ \\
\hline $\begin{array}{l}\text { Physical demands } \\
\text { Yes } \\
\text { No }\end{array}$ & $\begin{array}{l}1 \cdot 26 \\
1\end{array}$ & $0.93-1 \cdot 72$ & $\begin{array}{l}1 \cdot 18 \\
1\end{array}$ & $0.86-1.62$ \\
\hline $\begin{array}{l}\text { Emotional demands } \\
\text { High } \\
\text { Low } \\
\text { No }\end{array}$ & $\begin{array}{l}1.53 \\
1.49 \\
1\end{array}$ & $\begin{array}{l}1 \cdot 13-2 \cdot 09 \\
1 \cdot 07-2 \cdot 07\end{array}$ & $\begin{array}{l}1 \cdot 39 \\
1 \cdot 45 \\
1\end{array}$ & $\begin{array}{l}1 \cdot 01-1.91 \\
1.04-2 \cdot 04\end{array}$ \\
\hline $\begin{array}{l}\text { Conflicts supervisor } \\
\text { Yes } \\
\text { No }\end{array}$ & $\begin{array}{l}1 \cdot 10 \\
1\end{array}$ & $0 \cdot 60-2 \cdot 02$ & $\begin{array}{l}0.99 \\
1\end{array}$ & $0.53-1.83$ \\
\hline $\begin{array}{l}\text { Conflicts co-worker } \\
\text { Yes } \\
\text { No }\end{array}$ & $\begin{array}{l}1 \cdot 37 \\
1\end{array}$ & $0 \cdot 76-2 \cdot 46$ & $\begin{array}{l}1 \cdot 20 \\
1\end{array}$ & $0 \cdot 66-2 \cdot 18$ \\
\hline $\begin{array}{l}\text { Job insecurity } \\
\text { Yes } \\
\text { No }\end{array}$ & $\begin{array}{l}1 \cdot 03 \\
1\end{array}$ & $0 \cdot 62-1 \cdot 71$ & $\begin{array}{l}0 \cdot 94 \\
1\end{array}$ & $0.56-1 \cdot 59$ \\
\hline
\end{tabular}

$\dagger$ Adjusted for age, educational level, living alone, employment status and presence of disease.

* Adjusted for age, educational level, living alone, employment status, presence of disease and baseline CIS score (continuous).

for low decision latitude and conflicts with coworker were explained away.

As presented in Table 7 , in women low supervisor and co-worker social support were no longer associated with psychological distress when controlled for baseline CIS score. High psychological demands $(\mathrm{OR}=1.44(1.03-2.01))$ and high emotional demands, however, were predictive for the onset of psychological distress.

\section{DISCUSSION}

This prospective, longitudinal study showed that psychosocial work characteristics were significant predictors for the onset of fatigue during 1 year follow-up in the working population. Psychological demands at work as well as physical and emotional demands increased the risk for future fatigue in men, whereas decision latitude in men and co-worker social support in women were protective against future fatigue. As regards psychological distress, no association was found with decision latitude, while conflicts at work increased the risk of psychological distress in both genders, suggesting that work characteristics which predict fatigue may differ from those which predict psychological distress. The prospective associations between psychosocial work characteristics and either fatigue or psychological distress remained significant after adjustment for potential confounding factors and baseline measures of fatigue or psychological distress, strengthening our results which are based on self-reported data.

To our knowledge, this is the first time that psychosocial work characteristics have been analysed as determinants of future fatigue in the working population. Our results suggest predictive effects of a wide range of psychosocial work characteristics on fatigue in men and 
women. Overall, given the weak to modest intercorrelations of the psychosocial work characteristics, the predictive effects of the separate psychosocial work characteristics were quite similar to those obtained from analyses when all psychosocial work characteristics were entered together.

We found clear differences between men and women regarding the effects of work characteristics on fatigue after the adjustment for baseline fatigue. Notably, co-worker social support had a strong protective effect on future fatigue in women. In men, psychological, emotional and physical demands were predictive of fatigue, compared to decision latitude which remained significantly associated with lower fatigue scores. Somewhat unexpectedly, also job insecurity was found to be protective against future fatigue, when controlled for baseline measures in men. We have to keep in mind, however, that job insecurity was measured at baseline, while the follow-up of fatigue was 1 year later. Therefore, it is possible that when the threat of losing the job was removed - after all, the employees were still working 1 year laterthe employees high on job insecurity at baseline likely experienced a decline in insecurity, which was then associated with less fatigue at followup. Whether the observed gender differences with respect to the effects of psychosocial work characteristics on fatigue may be partly explained by differences in the structure of occupations and work characteristics for men and women (Lennon 1995) or by differences in the perception of work conditions requires further exploration.

Consistent evidence for predictive effects of psychosocial work characteristics on fatigue was found in the logistic regression analysis. The cutoff point for fatigue was empirically derived in a separate pilot study (Bültmann et al. 2000). Upon crossing the cut-off, an additional refinement of a minimum amount of increase was required, thereby excluding those who are close to the cut-off and make only a small change. Hence, we note that in our conservative strategy, the findings underline the strong protective effects of high social support at work in both genders, and suggest a strong impact of conflicts with co-workers in particular among women. Low decision latitude and high emotional demands were found to be strong predictive factors of fatigue in men, even after the adjustment for baseline psychological distress, which did not drastically weaken the associations and therefore shows the robustness of our findings. Thus, good interpersonal relationships at work and high decision latitude, especially decision authority, are of particular importance, and may be relevant aspects that should be addressed in workplace interventions.

The pattern of associations between psychosocial work characteristics and psychological distress showed partly similar and partly distinct effects compared to fatigue. In men, similar effects were found for psychological, emotional and physical demands, whereas conflicts at work was an important predictor of future psychological distress, but not of fatigue. Moreover, there was no effect of decision latitude on psychological distress. We found no prospective associations between psychosocial work characteristics and psychological distress in women after adjustment for baseline distress. The results of the logistic regression analysis, however, suggest differential effects of high emotional demands on psychological distress, while low decision latitude and bad relationships at work increased the risk of fatigue. One reason that psychosocial work characteristics might have a common effect on fatigue and psychological distress is because the two measures are correlated. Our prospective results, however, suggest some differential effects in the aetiology of fatigue versus psychological distress, which lends weight to the notion of the existence of two different concepts.

With respect to the present study, several issues have to be acknowledged. First, an overall response rate of $45 \%$ at baseline was reasonable for a survey in the working population, though a potential biasing of the results related to a selective participation of employees cannot be ruled out. A non-response analysis, however, demonstrated that non-respondents were less likely to report fatigue and sickness absence, which may have resulted in a slight overestimation of the level of fatigue. Regarding the response at follow-up, we have to recognize that non-respondents reported higher fatigue levels at baseline than respondents, which may have resulted in a slight underestimation of the cumulative 1-year incidence of fatigue. Nevertheless, we would like to emphasize that the 
response rate at follow-up was $80 \%$, and that the response was not affected by selective nonresponse from different sectors, trades and companies participating in the Maastricht Cohort Study.

A second issue concerns the time span between the assessment of psychosocial work characteristics, which reflect the condition at baseline, and the follow-up of fatigue and psychological distress of 1 year. Where most work characteristics were assumed to be relatively stable, others, like social support, job insecurity and conflicts at work could have changed during follow-up, so that the associations between these work characteristics and either fatigue or psychological distress would be attenuated. Frese \& Zapf (1988) extensively discussed of how work characteristics may affect ill-health in the course of time and presented different conceptual models. Moreover, they suggested that different outcomes of ill-health may follow different models. In order to clarify whether work characteristics have immediate, delayed or cumulative effects, to specify the impact of exposure changes on future fatigue and psychological distress, as well as to elucidate the time course of ill-health, repeated exposure and outcome assessments in a broader time-frame are required.

Following on this issue, the potential underlying effects of negative affectivity (NA) on the self-report nature of our measures (Watson \& Clark, 1984) have to be recognized. It is argued that individuals high on NA may perceive their work environment more negatively, thereby creating spurious associations between work characteristics and the reports of adverse health outcomes, which are also influenced by NA. Other authors (Stansfeld et al. 1998, 1999) have reported that work characteristics, although reduced in magnitude, remained associated with health functioning and psychiatric disorder after controlling for NA. However, in longitudinal analyses which adjust for baseline values of the outcome variable, the possible influence of NA is reduced. In our study, while negative affectivity is not measured, we adjusted for either baseline fatigue or psychological distress, thereby controlling for the influence of NA on baseline values. Moreover, to demonstrate the distinctness of the concepts of fatigue and psychological distress we also controlled for the other baseline measure which may lead to an overcorrection.
Finally, the present study focuses primarily on psychosocial work characteristics as risk factors for the onset of fatigue and psychological distress, while a broader, multi-factorial aetiology of fatigue is emphasized in the literature (Lewis \& Wessely, 1992). Thus, it is possible that other factors, such as work-family aspects (e.g. domestic load, leisure time activities) and individual characteristics (e.g. health behaviour, coping style), may play a role in the onset of fatigue and psychological distress. Although we have not yet examined these relationships, it seems unlikely that these factors would affect strongly the associations found here. Nevertheless, in our analyses the presence of disease at baseline was taken into account as a confounding variable, because it might influence the reporting of either psychosocial work characteristics or fatigue and psychological distress. The findings showed, however, that the associations between psychosocial work characteristics and either fatigue or psychological distress were independent of the presence of a disease.

In conclusion, the findings of this prospective study provide support for the predictive effects of psychosocial work characteristics on fatigue in the working population. These associations are independent of baseline fatigue. Moreover, the study supports differential effects of psychosocial work characteristics in the aetiology of fatigue versus psychological distress and suggests that they may operate in different ways for men and women. Given the considerable impact of fatigue and psychological distress on the individual worker, the employers and the society, these findings underline the need for interventions addressing the psychosocial work environment in order to prevent, or at least reduce, the risk of fatigue and psychological distress in the working population. However, future research should further elucidate the multifactorial aetiology of fatigue and psychological distress, thereby focusing on the role of workfamily factors and individual characteristics as well as their interplay with psychosocial work characteristics.

The Maastricht Cohort Study is part of The Netherlands concerted research action on 'Fatigue at work' granted by The Netherlands Organization for Scientific Research (NWO). The work presented in this paper was and is currently supported by The 
Netherlands Organization for Scientific Research (NWO grant no. 580-02.251).

\section{REFERENCES}

Beurskens, A. J., Bültmann, U., Kant, IJ., Vercoulen, J. H., Bleijenberg, G. \& Swaen, G. M. (2000). Fatigue among working people: validity of a questionnaire measure. Occupational \& Environmental Medicine 57, 353-357.

Bültmann, U., De Vries, M., Beurskens, A. J. H. M., Bleijenberg, G., Vercoulen, J. H. M. M. \& Kant, IJ. (2000). Measurement of prolonged fatigue in the working population: determination of a cutoff point for the Checklist Individual Strength. Journal of Occupational Health Psychology 5, 411-416.

Bültmann, U., Kant, IJ., Kasl, S., Beurskens, A. \& Van den Brandt, P. (2002a). Fatigue and psychological distress in the working population: psychometrics, prevalence, and correlates. Journal of Psychosomatic Research (in the press).

Bültmann, U., Kant, IJ., Schröer, K. \& Kasl, S. V. (2002b). The relationship between psychsosocial work characteristics and fatigue and psychological distress. International Archives of Occupational and Environmental Health (in the press).

Chen, M. K. (1986). The epidemiology of self-perceived fatigue among adults. Preventive Medicine 15, 74-81.

Frese, M. \& Zapf, D. (1988). Methodological issues in the study of work stress: Objective vs subjective measurement of work stress and the question of longitudinal studies. In Causes, Coping and Consequences of Stress at Work (ed. C. L. Cooper and R. Payne), pp. 375-411. Wiley: Chichester.

Goldberg, D. P. \& Williams, P. (1988). A User's Guide to the General Health Questionnaire. NFER-Nelson: Windsor.

Gründemann, R., Smulders, P. \& Winter de, C. (1993). Handleiding Vragenlijst Arbeid en Gezondheid [Questionnaire on Work and Health. Manual]. Swets \& Zeitlinger: Lisse.

Hardy, G. E., Shapiro, D. A. \& Borrill, C. S. (1997). Fatigue in the workforce of National Health Service Trusts: levels of symptomatology and links with minor psychiatric disorder, demographic, occupational and work role factors. Journal of Psychosomatic Research 43, 83-92.

Hickie, I. B., Hooker, A. W., Hadzi Pavlovic, D., Bennett, B. K., Wilson, A. J. \& Lloyd, A. R. (1996). Fatigue in selected primary care settings: sociodemographic and psychiatric correlates. Medical Journal of Australia 164, 585-588.

Houtman, I. (1995). Reliability and Validity of the Dutch Version of the Karasek Job Content Questionnaire. NIOSH/APA conference on Stress, Work, and Health. APA: Washington, DC.

Houtman, I. (1999). Feiten en fabels op een rij. Werkdruk in cijfers (Work pace in numbers). Arbeidsomstandigheden 75, 2-5.

Kant, IJ., Beurskens, A., Schröer, C., Nijhuis, F. \& Schayck van, C. (2000). De Maastrichtse Cohort Studie naar langdurige psychische vermoeidheid in de arbeidssituatie (The Maastricht Cohort Study of prolonged Fatigue at Work). Tijdschrift voor Bedrijfs- en Verzekeringsgeneeskunde 8, 226-232.

Karasek, R. A. (1985). Job Content Questionnaire and Users's Guide. University of Southern California, Department of Industrial and Systems Engineering: Los Angeles.

Koeter, M. W. J. \& Ormel, J. (1991). General Health Questionnaire, Handleiding Nederlandse bewerking (General Health Questionnaire, Manual Dutch Version). Swets \& Zeitlinger: Lisse.
Kroenke, K., Wood, D. R., Mangelsdorff, A. D., Meier, N. J. \& Powell, J. B. (1988). Chronic fatigue in primary care. Prevalence, patient characteristics, and outcome. Journal of the American Medical Association 260, 929-934.

Lennon, M. C. (1995). Work conditions as explanations for the relation between socioeconomic status, gender, and psychological disorders. Epidemiological Reviews 17, 120-127.

Lewis, G. \& Wessely, S. (1992). The epidemiology of fatigue: more questions than answers. Journal Epidemiology Community Health 46, 92-97.

Loge, J. H., Ekeberg, O. \& Kaasa, S. (1998). Fatigue in the general Norwegian population: normative data and associations. Journal of Psychosomatic Research 45, 53-65.

Niedhammer, I., Goldberg, M., Leclerc, A., Bugel, I. \& David, S. (1998). Psychosocial factors at work and subsequent depressive symptoms in the Gazel cohort. Scandinavian Journal of Work, Environment and Health 24, 197-205.

Pawlikowska, T., Chalder, T., Hirsch, S. R., Wallace, P., Wright, D. J. \& Wessely, S. C. (1994). Population based study of fatigue and psychological distress. British Medical Journal 308, 763-766.

Schröer, C. A. P. (1997). De toename van arbeidsongeschiktheid wegens psychische aandoeningen (The increase of work disability due to mental disorders). Tijdschrift voor Bedrijfs- en Verzekeringsgeneeskunde 5, 16-23.

SPSS (1998). Base 9.0 for Windows User's Guide. SPSS Inc.: Chicago. Stansfeld, S. A., Bosma, H., Hemingway, H. \& Marmot, M. G. (1998). Psychosocial work characteristics and social support as predictors of SF-36 health functioning: the Whitehall II study. Psychosomatic Medicine 60, 247-255.

Stansfeld, S. A., Fuhrer, R., Head, J., Ferrie, J. \& Shipley, M. (1997). Work and psychiatric disorder in the Whitehall II Study. Journal of Psychosomatic Research 43, 73-81.

Stansfeld, S. A., Fuhrer, R., Shipley, M. J. \& Marmot, M. G. (1999). Work characteristics predict psychiatric disorder: prospective results from the Whitehall II Study. Occupational \& Environmental Medicine 56, 302-307.

Van Veldhoven, M. \& Meijman, T. (1994). Het meten van psychosociale arbeidsbelasting met een vragenlijst: De Vragenlijst Beleving en Beoordeling van de Arbeid (VBBA) (Questionnaire on Perception and Judgement of Work). NIA: Amsterdam.

Vercoulen, J. H., Swanink, C. M., Fennis, J. F., Galama, J. M., van der Meer, J. W. \& Bleijenberg, G. (1994). Dimensional assessment of chronic fatigue syndrome. Journal of Psychosomatic Research 38, 383-392.

Vercoulen, J. H., Hommes, O. R., Swanink, C. M., Jongen, P. J., Fennis, J. F., Galama, J. M., van der Meer, J. W. \& Bleijenberg, G. $(1996 a)$. The measurement of fatigue in patients with multiple sclerosis. A multidimensional comparison with patients with chronic fatigue syndrome and healthy subjects. Archives of Neurology 53, 642-649.

Vercoulen, J. H., Swanink, C. M., Fennis, J. F., Galama, J. M., van der Meer, J. W. \& Bleijenberg, G. (1996b). Prognosis in chronic fatigue syndrome: a prospective study on the natural course. Journal of Neurology, Neurosurgery and Psychiatry 60, 489-494.

Vercoulen, J. H. H. M., Alberts, M. \& Bleijenberg, G. (1999). De Checklist Individuele Spankracht (CIS) (The Checklist Individual Strength (CIS)). Gedragstherapie 32, 131-136.

Wall, T. D., Bolden, R. I., Borrill, C. S., Carter, A. J., Golya, D. A., Hardy, G. E., Haynes, C. E., Rick, J. E., Shapiro, D. A. \& West, M. A. (1997). Minor psychiatric disorder in NHS trust staff: occupational and gender differences. British Journal of Psychiatry 171, 519-523.

Watson, D. \& Clark, L. A. (1984). Negative affectivity: the disposition to experience aversive emotional states. Psychological Bulletin 96, 465-490. 